\title{
Genetic and Environmental Influences on Individual Differences in Attitudes Toward Homosexuality: An Australian Twin Study
}

\author{
Karin J. H. Verweij · Sri N. Shekar · Brendan P. Zietsch • \\ Lindon J. Eaves · J. Michael Bailey · Dorret I. Boomsma • \\ Nicholas G. Martin
}

Received: 21 June 2007/ Accepted: 28 February 2008/Published online: 18 March 2008

(C) The Author(s) 2008

\begin{abstract}
Previous research has shown that many heterosexuals hold negative attitudes toward homosexuals and homosexuality (homophobia). Although a great deal of research has focused on the profile of homophobic individuals, this research provides little theoretical insight into the aetiology of homophobia. To examine genetic and environmental influences on variation in attitudes toward homophobia, we analysed data from 4,688 twins who completed a questionnaire concerning sexual behaviour and attitudes, including attitudes toward homosexuality. Results show that, in accordance with literature, males have significantly more negative attitudes toward homosexuality than females and non-heterosexuals are less homophobic than heterosexuals. In contrast with some earlier findings, age had no significant effect on the homophobia scores in this study. Genetic modelling showed that variation in homophobia
\end{abstract}

Edited by Hermine Maes.

K. J. H. Verweij ( $\square)$ · S. N. Shekar · B. P. Zietsch .

N. G. Martin

Genetic Epidemiology Laboratory, Queensland Institute of

Medical Research, 300 Herston Road, Brisbane 4029, QLD,

Australia

e-mail: karinverweij@hotmail.com

K. J. H. Verweij · D. I. Boomsma

Department of Biological Psychology, VU University,

Amsterdam, The Netherlands

\section{J. Eaves}

Virginia Institute for Psychiatric and Behavioral Genetics,

Virginia Commonwealth University School of Medicine,

Richmond, VA, USA

J. M. Bailey

Department of Psychology, Northwestern University, Evanston, IL, USA scores could be explained by additive genetic (36\%), shared environmental $(18 \%)$ and unique environmental factors (46\%). However, corrections based on previous findings show that the shared environmental estimate may be almost entirely accounted for as extra additive genetic variance arising from assortative mating for homophobic attitudes. The results suggest that variation in attitudes toward homosexuality is substantially inherited, and that social environmental influences are relatively minor.

Keywords Attitudes - Genetics - Heritability · Homophobia · Twin study · Homosexuality

\section{Introduction}

Homophobia can be defined as 'the fear of, aversion to, or discrimination against homosexuality or homosexuals' (Merriam-Webster's Medical Dictionary 2007). Although the social and cultural status of homosexuality has improved, Kite and Whitley (1996) concluded from their meta-analyses of 112 studies that many heterosexuals still hold very negative attitudes toward homosexuals and their sexual behaviour. A great deal of research has focused on the personality and demographic features of homophobic individuals. Numerous studies indicated that men tend to hold more negative attitudes toward homosexuals than women, especially toward gay men (e.g. Davies 2004; Herek 1988; Herek and Gonzalez-Rivera 2006; Kite and Whitley 1996; LaMar and Kite 1998; Lingiardi et al. 2005; Steffens and Wagner 2004). The most common explanation for this sex difference in homophobic attitudes is that men tend to hold more traditional gender beliefs, which encourage them to be more negative toward homosexuality, particularly toward gay men (Kite and Whitley 1996). Furthermore, 
homophobic individuals in general seem to be higher in authoritarianism, are more religious, hold traditional attitudes toward family and gender roles, have relatively low levels of education and have had fewer interactions with homosexuals (Herek 1988, 2002; Herek and Gonzalez-Rivera 2006). As Kite and Whitley (1996) stated, these data offer some insight into the profile of homophobic individuals, but the existing research is only descriptive in nature and hence provides little theoretical insight into prejudices regarding sexual orientation.

There is considerable support for the existence of generalized prejudice (see Ekehammar et al. 2004). Different types of prejudice (e.g. racism, sexism and prejudice toward homosexuals) have been shown to be highly correlated (e.g. Bierly 1985; Ekehammar and Akrami 2003), implying that people who reject one out-group will also tend to reject others. As Ekehammar et al. (2004) describe in their article, two major theories have risen to explain why some individuals are more prejudiced than others. In the first theory, individual differences in prejudice are considered to be due to stable factors within the individual (their personality characteristics); in this case prejudice is seen as an expression of personality (Ekehammar and Akrami 2003; Heaven and St. Quintin 2003). The second theory implies that individual differences in prejudice are caused by factors linked to the outside world, like intergroup relationships and social life (see e.g. Guimond et al. 2003; Guimond 2000; Reynolds et al. 2001).

Earlier twin studies have demonstrated that individual differences in personality are substantially heritable (e.g. Jang et al. 1996; Loehlin et al. 1998), and therefore, it is possible that there are genetic influences on homophobia as well. On the other hand, a study concerning personality and social attitudes (including general conservatism and attitude to sex and politics) in a large sample revealed that, besides genetic effects, family (shared) environment also has a considerable contribution to social attitudes (Eaves et al. 1999). Consequently, shared environmental influences on attitudes toward homosexuality can also be expected. Such results would fit the second theory that emphasizes social processes.

Accordingly, the aim of the present study is to determine the contribution of both genes and shared environment to individual differences in attitudes to homosexuality, using data from a large twin sample. Findings will result in further insight into the aetiology of variation in homophobia.

\section{Methodology}

Participants

All participants were drawn from the Australian National Health and Medical Research Council Twin Registry
(ATR). Subjects for this study were recruited in two phases from a large twin-family study of alcohol use and abuse.

In phase one, all twin pairs $(N=4,269$, aged between 18 and 25 years) participating in an extensive Health and Lifestyle Questionnaire (HLQ) were asked whether they were willing to participate in an anonymous study about sexual behaviour and attitudes. All those who agreed were mailed the sex questionnaire between July 1991 and October 1992. To ensure anonymity, twins were not asked about their name or date of birth, but to make up a 10 digit number. Both twins of a pair had to use the same number, which made it possible to connect the responses of both twins. Additionally, informed consent was obtained separate from the questionnaires.

In the second phase, an additional group of twin pairs in an older cohort (aged between 27 and 52 years old) was asked to participate in the sexual behaviour and attitudes study. Procedures for this data collection were the same as for the younger cohort, as described above. Twins who expressed willingness to participate were mailed the questionnaire between April and August 1992. For a more extensive description of the data collection procedure, the study sample, and the pairing of the returned questionnaires (see Kirk et al. 2000).

In total, 1,907 complete pairs and 1,090 twins from incomplete pairs completed the questionnaire $(1,824$ male and 3,080 female individuals). However, due to missing data and ambiguous zygosities the effective study sample used for the homophobia analyses is lower than 4,904, as described in the result section.

\section{Zygosity}

The zygosity of the same-sex twins was determined during completion of the HLQ, based on their response to standard items about physical similarity and being mistaken for each other. Ambiguous replies were clarified by telephone call. According to Ooki et al. (1990) and Martin and Martin (1975), concurrence on zygosity between discriminant analyses of questionnaire scores and DNA typing is at least 95\% and telephone clarification will have increased accuracy. In the present study the zygosity of the twin pairs was premarked on their questionnaire and the twins were asked whether they did or did not agreed with the assessment.

\section{Measures}

Data used in this study were 10 items from a larger part of the sexual behaviour and attitudes questionnaire called 'Your Present Personality'. This part of the questionnaire contained 47 items, selected from three former instruments, namely: Inventory of Attitudes to Sex (30 items; Eysenck 1976), Attitudes to Homosexuality (10 items; Klassen et al. 
1989) and Adult Gender Nonconformity (seven items; Finn 1987, The structure of masculinity and femininity self ratings, Unpublished manuscript). A principal components analysis of these 47 items (performed in SPSS-13.0 for Windows) revealed nine factors for males and 10 for females. The most apparent factor for both sexes, explaining $16 \%$ of the total variance for both sexes, was a factor regarding attitudes to homosexuality, comprising all 10 items of the Attitudes to Homosexuality scale created by Klassen et al. (1989). Each item showed a high factor loading for both males and females (between 0.55 and 0.87).

Accordingly, in the present study homophobia was measured using the 10 items of this Attitudes to Homosexuality scale, which comprised statements like 'Homosexuality is obscene and vulgar', and 'Homosexual men should be allowed to work as schoolteachers' (see Appendix A for the total scale). Twins were asked to either tick YES if they agreed with the statement or NO if they disagreed. If a participant filled out both answers on an item (both YES and NO), the item was coded as missing. To enhance unbiased answering, a preamble to the section explained that there are no right or wrong answers and no trick questions and they were encouraged to work quickly and not to think too long about the exact meaning of questions.

To maximise the number of twin pairs available for genetic analysis, missing item responses were imputed where possible by using the imputation methods in PRELIS 2.30 (Jöreskog and Sörbom 1999). Missing values were substituted with values from other cases with similar response patterns, but without missing data. Note that it was only possible to impute items in PRELIS if participants had only one missing value and that imputation depended on the response patterns from other cases. A total of 109 responses were imputed $(0.2 \%$ of the total item responses), increasing the available twins for structural equation modelling from 4,442 to 4,551 , a gain of $2.5 \%$ in the total available sample size.

A total homophobia score was calculated by summing the answers on all 10 statements, where a homophobic response was counted as one and a non-homophobic response as zero. To further maximise the number of twin pairs available for genetic analysis, participants missing one $(N=116)$ or two $(N=101)$ responses were included in further analyses. Their homophobia score was corrected by adding their mean item score for each missing item. This resulted in another gain of $4.8 \%$ of the available sample size.

As the distribution of the homophobia data showed significant skewness and kurtosis, scores were grouped into four ordinal categories with roughly equal sample sizes. Individuals scoring 0 on the continuous scale were given an ordinal score of 0 , while individuals scoring 1 or 2 were given score 1, individuals scoring 3-6 score 2, and individuals scoring $7-10$ score 3 .

To determine the participants' sexual orientation, twins were asked the following question in another part of the questionnaire, called 'Sexual Feelings and Behaviour': Do you consider yourself to be heterosexual (straight), bisexual or homosexual (lesbian or gay)? For the present study, sexual orientation was only subdivided into heterosexual and non-heterosexual. The latter includes both bisexual and homosexual individuals.

\section{Data analysis}

As the homophobia scale analysed in this study is an ordinal scale, the data were analysed using a threshold model (Falconer 1989). For these analyses it is assumed that there is an underlying continuum of liability which is normally distributed in the population. Upon this normal distribution three thresholds are placed to delimit the four categories. Variation in liability can be modelled as a function of genetic and environmental influences.

Descriptive statistics for the homophobia scores are obtained using SPSS-13.0 for Windows. Subsequently, Structural Equation Modelling (SEM) is applied to estimate thresholds, polychoric correlations between twins and components of variance. First, the effects of gender, age and sexual orientation on the thresholds is tested. Next, heterogeneity of polychoric twin pair correlations was assessed as a function of sex and zygosity, and finally the importance of different sources of familial aggregation (i.e. shared genes and shared environment) was tested. SEM is conducted using Mx $1.65 \mathrm{~b}$, a matrix algebra calculator that fits structural equation models to observed data (Neale et al. 2003). All analyses were conducted using maximumlikelihood estimation for raw ordinal data in Mx. Models were compared with a likelihood ratio $\chi^{2}$ test.

To determine the effects of age, sexual orientation and sex on the thresholds, different (nested) submodels are tested against a full model, in which all parameters were estimated. By looking for differences in model fit after constraining these effects to zero in a stepwise manner, the significance of parameters that contribute to explaining differences in thresholds can be determined.

Heterogeneity of twin pair correlations is tested by determining the change in model fit when twin pair correlations (for sex and/or zygosity) were equated.

Genetic model fitting of twin data allows for decomposition of the observed variance in homophobia scores into its genetic and environmental components. Additive genetic variance $(\mathrm{A})$ denotes the variance resulting from the sum of allelic effects across multiple genes, while D symbolizes non-additive genetic effects including 
dominance and epistasis. Common environmental variance (C) is that resulting from environmental influences shared within twin pairs, whereas unique environmental variance (E) results from non-shared environmental influences and includes measurement error. Estimates of A, C, D and E can be derived from the resemblance between monozygotic (MZ) twins who are genetically identical and dizygotic (DZ) twins who share, on average, $50 \%$ of their segregating genes. Accordingly, if MZ twins resemble each other more than DZ twins on a particular trait, this is an indicator that it is partly influenced by genetic effects. Further, if the DZ within-pair correlation is higher than half the MZ within-pair correlation, this implies that common environmental effects contribute to individual differences in the homophobia scores. By means of SEM, different combinations of $\mathrm{A}, \mathrm{C}, \mathrm{D}$, and $\mathrm{E}$ can be evaluated to obtain the most parsimonious explanation for the observed pattern of $\mathrm{MZ}$ and DZ twin pair correlations. Note, however, that $\mathrm{C}$ and D cannot be estimated simultaneously (Martin et al. 1978) and that the choice for an ACE or ADE model depends on the pattern of MZ and DZ correlations.

\section{Results}

\section{Descriptive statistics}

Of the 4,904 respondents to the questionnaire, 136 were omitted as they had more than two missing values on the 10 homophobia items and an additional 80 single twins were deleted due to ambiguous zygosity. Hence the total number of individuals utilised for the analyses is 4,688 , comprising 2,846 twin families (1,822 pairs and 1,044 singletons). Complete twin pairs included $295 \mathrm{MZ}$ males, $182 \mathrm{DZ}$ males, $634 \mathrm{MZ}$ females, $354 \mathrm{DZ}$ females and $357 \mathrm{DZ}$ opposite sex pairs. The age range of the study sample was 19-52 years for both sexes, with a mean age for males of 30.6 (S.D. $=8.3$ ) and for females of 31.1 (S.D. $=8.5$ ). Descriptive statistics for each homophobia statement for all individuals are presented in Table 1.

Using the imputed data set, item scores were added together and subsequently recoded into a four-point ordinal scale ranging from 0 (not homophobic at all) to 3 (highly homophobic). Table 2 shows the number and percentage of individuals within each homophobia category.

To determine whether sexual orientation influences homophobic attitudes, individuals were asked which sexual orientation they considered themselves. Of the 1,758 male participants, 1,627 $(92.5 \%)$ rated themselves as heterosexual, while $111(6.3 \%)$ considered themselves to be nonheterosexual [20 responses $(1.1 \%)$ were missing]. Of the 2,930 females, 2,802 (96.6\%) rated themselves to be heterosexual, while $100(3.4 \%)$ considered themselves to be non-heterosexual [28 responses $(1.0 \%)$ were missing]. In Table 2 the number and percentage of heterosexuals and non-heterosexuals within each homophobia category is shown.

Hypotheses concerning differences in threshold parsimony

Within sexes, thresholds for MZ and DZ twins could be equated without significant deterioration in model fit $\left(\chi_{12}^{2}=8.60, P=0.74\right)$, indicating no evidence for social interaction between twins. However, results show a significant difference in the distribution of attitudes toward homosexuality between sexes, such that males were more homophobic than females $\left(\chi_{3}^{2}=80.41, \quad P<0.001\right)$. Furthermore, a significant difference in distribution of thresholds was found between heterosexuals and

Table 1 Percentage of agreement (yes), disagreement (no) and missing answers on the 10 homophobia statements for males and females separately

\begin{tabular}{|c|c|c|c|c|c|c|}
\hline & \multicolumn{3}{|c|}{ Males $(N=1,758)$} & \multicolumn{3}{|c|}{ Females $(N=2,930)$} \\
\hline & Yes & No & Missing & Yes & No & Missing \\
\hline Homosexuality is not immoral & 50.9 & 48.2 & 0.9 & 64.0 & 35.1 & 1.0 \\
\hline Allow as school teachers & 53.0 & 46.9 & 0.1 & 69.4 & 30.5 & 0.0 \\
\hline Allow as court judges & 65.2 & 34.7 & 0.1 & 78.4 & 21.4 & 0.2 \\
\hline Allow as ministers & 56.9 & 43.0 & 0.1 & 67.4 & 32.2 & 0.4 \\
\hline Allow as medical doctors & 58.0 & 41.9 & 0.1 & 70.1 & 29.8 & 0.1 \\
\hline Allow as government officials & 70.8 & 29.1 & 0.1 & 81.8 & 18.1 & 0.1 \\
\hline Dangerous as teachers ${ }^{\mathrm{a}}$ & 34.4 & 63.4 & 2.2 & 20.3 & 77.8 & 1.9 \\
\hline Homosexuality is obscene $^{\mathrm{a}}$ & 48.0 & 51.3 & 0.7 & 30.3 & 68.6 & 1.1 \\
\hline Homosexuality is social corruption $^{a}$ & 29.2 & 69.3 & 1.5 & 19.9 & 77.7 & 2.4 \\
\hline Allow to dance with each other in public & 49.1 & 49.2 & 1.7 & 62.2 & 35.2 & 2.6 \\
\hline
\end{tabular}

${ }^{a}$ Note that agreement on these statements indicate a homophobic attitude 
Table 2 Number and percentage of males and females, heterosexuals and non-heterosexuals, for each category of the ordinal homophobia scale ( 0 is least, 3 is most homophobic)

\begin{tabular}{|c|c|c|c|c|}
\hline Homophobia category & 0 & 1 & 2 & 3 \\
\hline Males, heterosexual $(N=1,627)$ & $368(22.6 \%)$ & $314(19.3 \%)$ & $392(24.1 \%)$ & $553(34.0 \%)$ \\
\hline Males, non-heterosexual $(N=111)$ & $77(69.4 \%)$ & $18(16.2 \%)$ & $13(11.7 \%)$ & $3(2.7 \%)$ \\
\hline Males $(N=1758)^{\mathrm{a}}$ & $450(25.6 \%)$ & $338(19.2 \%)$ & $408(23.2 \%)$ & $562(32.0 \%)$ \\
\hline Females, heterosexual $(N=2802)$ & $1,011(36.1 \%)$ & $692(24.7 \%)$ & $580(20.7 \%)$ & $519(18.5 \%)$ \\
\hline Females, non-heterosexual $(N=100)$ & $78(78.0 \%)$ & $9(9.0 \%)$ & $10(10.0 \%)$ & $3(3 \%)$ \\
\hline Females $(N=2930)^{\mathrm{a}}$ & $1,098(37.5 \%)$ & $705(24.1 \%)$ & $600(20.5 \%)$ & $527(18.0 \%)$ \\
\hline
\end{tabular}

${ }^{a}$ Note that for 20 males and 28 females self-reported sexual orientation is missing

non-heterosexuals $\left(\chi_{1}^{2}=192.51, P<0.001\right)$. On average, heterosexuals were more homophobic than nonheterosexuals.

Finally, it was tested whether age had a significant influence on the distribution of the thresholds. Removing the effect of age from the model did not lead to a significantly worse model fit $\left(\chi_{1}^{2}=1.83, P=0.18\right)$, implying that age has no appreciable influence on individual differences in attitudes toward homosexuality.

Heterogeneity of twin pair correlations

Polychoric twin pair correlations for each zygosity group, shown in Table 3, were estimated in Mx by maximumlikelihood. Although the twin pair correlation for MZ males is higher than for MZ females, they were not significantly different $\left(\chi_{1}^{2}=3.18, P=0.08\right)$.

Furthermore, as the twin pair correlation for DZ opposite sex twin pairs is lower than for the DZ same sex twin pairs, qualitative differences in sources of familial aggregation between sexes could be expected. However, the difference in twin pair correlation between the opposite and the same sex DZ twin pairs was not significant $\left(\chi_{2}^{2}=2.46\right.$, $P=0.29$ ).

The inability to find significant differences between the MZ twin pair correlations for males and females, and between the DZ same sex and opposite sex twin pair correlations may, however, be due to a lack of power to detect qualitative and quantitative differences between the groups.

The MZ twin pair correlations are significant higher than the DZ twin pair correlations $\left(\chi_{1}^{2}=15.64, P<0.001\right)$, suggesting that genetic effects are a source of familial aggregation in attitudes toward homosexuality.

Genetic modelling

Results of the univariate SEM for the homophobia scores are shown in Table 4. As the DZ twin pair correlations are more than half the MZ twin pair correlations, a model is fitted incorporating additive genetic (A), shared environmental (C) and unique environmental (E) effects. Since the DZ opposite sex correlation is lower (although not significantly) than the DZ same sex correlations, a general sexlimitation model is fitted, which allows for qualitative and quantitative differences in the sources of variation in attitudes toward homosexuality between sexes (Neale and Cardon 1992). To model the qualitative differences in genetic effects between sexes, the genetic correlation for DZ opposite sex twins $(\mathrm{H})$ is estimated in the model instead of fixed at 0.5 as it is for same sex DZ twin pairs.

Subsequently, a common effects sex-limitation model is fitted, by fixing the genetic correlation for DZ opposite sex twins at 0.5 . Results show no significant deterioration of model fitting $\left(\chi_{1}^{2}=1.43, P=0.23\right)$, consistent with the

Table 3 Polychoric twin pair correlations (95\% confidence intervals) for the homophobia score for each zygosity group, estimated in Mx

\begin{tabular}{llllll}
\hline & MZM 295 pairs & DZM 182 pairs & MZF 634 pairs & DZF 354 pairs & DZOS 357 pairs \\
\hline Correlation & $0.61(0.52-0.69)$ & $0.42(0.37-0.55)$ & $0.51(0.43-0.57)$ & $0.39(0.28-0.50)$ & $0.29(0.17-0.41)$ \\
\hline
\end{tabular}

Table 4 Genetic model fitting: Comparison of different genetic models

\begin{tabular}{|c|c|c|c|c|c|c|c|c|}
\hline & Model & -211 & d.f. & Vs & $\Delta \chi^{2}$ & $\Delta$ d.f. & P-value & $\mathrm{H}_{\text {Dzos }}$ \\
\hline 1 & General sex-limitation model & $12,199.93$ & 4672 & & & & & 0.09 \\
\hline 2 & Common effects sex-limitation model & $12,201.36$ & 4673 & 1 & 1.43 & 1 & 0.23 & 0.50 \\
\hline 3 & General ACE model & $12,205.88$ & 4675 & 2 & 4.52 & 2 & 0.10 & 0.50 \\
\hline
\end{tabular}


same sets of genes influencing homophobia scores for males and females.

Third, the fit of a general ACE model, in which proportions of $\mathrm{A}$ and $\mathrm{C}$ are constrained equal in males and females, is compared with the fit of the common effects sex-limitation model. Results show no significant deterioration of model fit $\left(\chi_{2}^{2}=4.52, P=0.10\right)$, indicating there are no magnitude differences in effects of $\mathrm{A}, \mathrm{C}$ and $\mathrm{E}$ on variance in homophobia scores between sexes.

Under the general ACE model, additive genetic and common environmental effects together account for between $48 \%$ and $59 \%$ of the variance in homophobia (see Table 5). It is impossible to distinguish between $\mathrm{AE}$ and $\mathrm{CE}$ models, as removing the effects of either $\mathrm{A}$ or $\mathrm{C}$ causes significant deterioration in model fit.

Accordingly, the most parsimonious explanation for the observed pattern of $\mathrm{MZ}$ and DZ twin pair correlations is the general ACE model, where there are no qualitative and quantitative differences in sources of variance between sexes. The twin pair correlations, however, point to possible differences in the sources of variance between sexes. The inability to detect these qualitative and quantitative differences between sexes might be due to insufficient power from using a threshold model, necessitated by the extreme skewness of the raw data (Neale et al. 1994).

Based on the general ACE model, estimates of the influence of $\mathrm{A}, \mathrm{C}$ and $\mathrm{E}$ on the variance in homophobia scores for both sexes are $36 \%, 18 \%$ and $46 \%$ (see Table 5). In Fig. 1, the graphical illustration of the general ACE model (a) and the general sex-limitation model (b), including the path coefficients, are presented.

\section{Discussion}

Analyses of the homophobia scale showed that, in accordance with former literature (e.g. Kite and Whitley 1996), males have more negative attitudes toward homosexuality than females and heterosexuals are more homophobic than non-heterosexuals (Jellison et al. 2004). In this study, age had no effect on attitudes toward homosexuality, whereas some others have found that younger individuals have more favourable attitudes regarding homosexuality than older persons (Herek 2002; Steffens and Wagner 2004). It should be noted however that the distribution of age in this study was highly skewed, with the majority of participants (70.9\%) in age group $19-35$ and only $29.1 \%$ of all participants aged between 35 and 52 years.

The aim of the present study was to determine the contribution of genes and environment to individual differences in attitudes toward homosexuality. Based on the general ACE model, estimates of the influence of $\mathrm{A}, \mathrm{C}$ and E on the variance in homophobia scores are: $36 \%, 18 \%$ and

\section{a General ACE model}

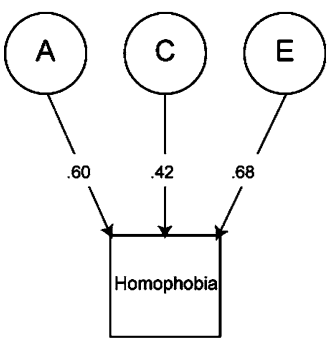

b General sex-limitation model

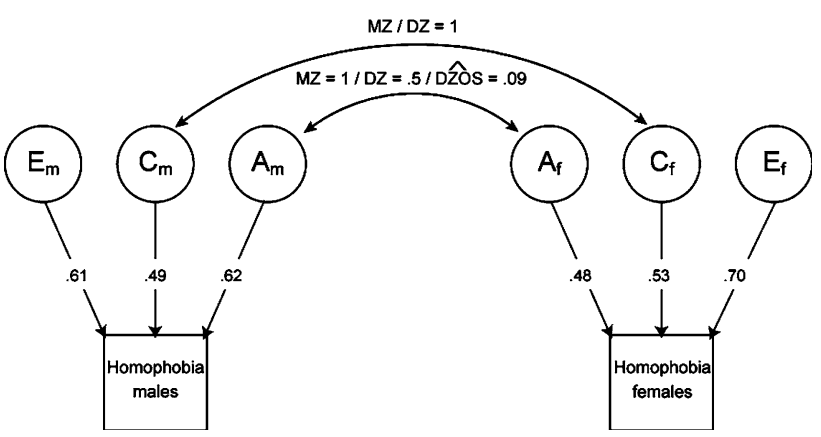

Fig. 1 Graphical presentation of the general ACE model (a) and the general sex-limitation model (b) along with the standardised path coefficients. In the general sex-limitation model path coefficients for males are presented on the left and for females on the right side. Note that in the general sex-limitation model the correlation between opposite sex twins for additive genetic effects $(D \hat{Z} O S)$ is estimated in the model

Table 5 Proportions of variance (95\% confidence intervals) attributable to A, C and E effects for both sexes for the general sex-limitation model, the common effects sex-limitation model and the general ACE model

\begin{tabular}{llllllll}
\hline & $\mathrm{A}_{\text {males }}$ & $\mathrm{C}_{\text {males }}$ & $\mathrm{E}_{\text {males }}$ & $\mathrm{A}_{\text {females }}$ & $\mathrm{C}_{\text {females }}$ & $\mathrm{E}_{\text {females }}$ & $\mathrm{H}_{\text {Dzos }}$ \\
\hline $\begin{array}{c}\text { General sex- } \\
\text { limitation model }\end{array}$ & $0.38(0.08-0.68)$ & $0.23(0.00-0.49)$ & $0.39(0.31-0.44)$ & $0.23(0.00-0.49)$ & $0.28(0.04-0.49)$ & $0.49(0.43-0.57)$ & 0.09 \\
$\begin{array}{c}\text { Common effects sex- } \\
\text { limitation model }\end{array}$ & $0.55(0.16-0.69)$ & $0.07(0.00-0.47)$ & $0.38(0.30-0.47)$ & $0.20(0.00-0.54)$ & $0.30(0.00-0.51)$ & $0.50(0.43-0.58)$ & 0.50 \\
\begin{tabular}{c} 
General ACE model \\
\hline
\end{tabular} & $0.36(0.19-0.54)$ & $0.18(0.02-0.32)$ & $0.46(0.41-0.52)$ & $0.36(0.19-0.54)$ & $0.18(0.02-0.32)$ & $0.46(0.41-0.52)$ & 0.50 \\
\hline
\end{tabular}


46\%. However, although no significant qualitative and quantitative differences in sources of variation between males and females were found, twin pair correlations do suggest possible differences between the sexes. Under a general sex-limitation model, estimates of the influence of $\mathrm{A}$ and $\mathrm{C}$ on variation in homophobia scores are $38 \%$ and $23 \%$ for males and $23 \%$ and $28 \%$ for females, respectively. The additive genetic correlation for the DZ opposite sex twins is estimated at 0.09 , considerably lower than the 0.5 assumed for DZ same sex twins. This finding would suggest that genes influencing homophobia in males are to a large extent different from those in females. However, since both $\mathrm{A}$ and $\mathrm{C}$ effects are present in both sexes, the parameterisation of sex limitation as genetic in origin is arbitrary. If it were parameterised as a lower common environmental correlation between males and females, the same model fit would be obtained. Moreover, there could be sex limitation of both $\mathrm{A}$ and $\mathrm{C}$ influences, but since there is only one degree of freedom to estimate themobtained from the DZ opposite sex twin pair correlationthe two are completely confounded. In either case, differences in saliency of homosexuality between males and females make it unsurprising that there are distinct causes of variation in homophobia in the two sexes.

A limitation to our confidence in the variance components estimated above is that strong assortative mating has been repeatedly found for social attitudes (e.g. Eaves et al. 1999; Hatemi et al. 2007; Martin et al. 1986). This means that the relative genetic variance may have been underestimated. If spouses are correlated for homophobia through the assortment process, then both $\mathrm{MZ}$ and DZ twin correlations will be raised to the same degree. Mimicking the effect of shared environment this extra resemblance would yield higher estimates of ' $C$ '. As our sample does not include spouses, we rely on previous estimates of assortative mating to determine its effect on our estimates. Recently, Hatemi et al. (2007) investigated spouse correlations on social attitudes, including an item on gay rights, for which they found a spouse correlation of 0.58 . Assuming that this value is a reasonable estimate for assortative mating in our sample, it is possible to correct our $\mathrm{C}$ estimate for assortative mating by using a procedure described by Martin (1978). ${ }^{1}$

After correction, the contribution of shared environment on individual differences in homophobia scores falls from 0.18 to 0.03 , while the genetic estimate increases to about 0.51. This finding suggests that variation in attitudes

\footnotetext{
${ }^{1}$ Martin (1978) used the following formula to correct $\mathrm{C}$ for assortative mating: $c_{\text {adj }}^{2}=c_{R}^{2}-h_{R}^{2} A /(1-A)$, where $h_{\mathrm{R}}^{2}$ and $c_{\mathrm{R}}^{2}$ are the relative genetic and common environmental effects as estimated by the model, and $A$ is the correlation between additive genetic values of mates, and is a function of the observed value for assortative mating $(\mu)$ and $h_{R}^{2} ; A=0.5 *\left[1-\sqrt{ }\left(1-4 \mu h_{R}^{2}\right)\right]$.
}

toward homosexuality is substantially inherited, while social environmental influences are relatively minor.

When applying the assortative mating correction to the results of the general sex-limitation model, the contribution of shared environment on individual differences in homophobia scores for males falls from 0.23 to 0.04 and for females from 0.28 to 0.24 , while the genetic estimate increases to about 0.57 for males and 0.27 for females. As such, based on the general sex-limitation model familial aggregation for homophobia scores for males might be almost totally accounted for by genetic effects, while for females both genes and shared environment seem to have about equal effects. If this would be the case, and there is little or no $\mathrm{C}$ influence on homophobia scores for males, sex limitation for homophobia scores can only have a genetic origin.

Another important consideration is that the genetic contribution to homophobia might partly reflect genetic influences on related traits such as intelligence, personality, or social class. In our data, the polychoric correlation of the homophobia measure with educational level was -0.27 $(P<0.01)$ and with social class was $-0.14(P<0.01)$, so these traits would only account for a modest amount of variance.

While individuals' attitudes toward homosexuality are partly influenced by genes, shared environmental factors also contribute a modest proportion of variation in homophobic attitudes. This finding suggests that shared environmental influences, such as norms and values taught by parents, are aspects in forming positive or negative attitudes toward homosexuals, and possibly also toward other out-groups. The main source of variance is unique environment ( $46 \%$ under the general ACE model). While an unknown fraction of this will be due to measurement error, the number suggest a great influence on attitudes to homosexuality is the unique experiences of the individual shaping his or her attitudes independent of family influences. This study shows that one's own sexual orientation is one such influence, although previous research has shown that sexual orientation itself is substantially genetically influenced (e.g. Kendler et al. 2000; Kirk et al. 2000). Although the effect of sexual orientation on homophobia is large at the individual level, the percentage of non-heterosexuals is so low, it accounts for only a trivial proportion of population variance in attitudes to homosexuality.

There are a few important methodological limitations to be considered for this study. As already mentioned, the most important limitation of this study was a lack of statistical power. Although the sample size is fairly large, due to the fact that the homophobia scale had to be analysed as ordinal data, it is still insufficient. Neale et al. (2004) showed that for a threshold study at least three times the 
sample size needed for equivalent power to a study using continuous data is required.

Another important limitation of this study is that no distinction has been made between attitudes toward male versus female homosexuals. Five out of the ten questions are asked in gender neutral terms, while the other five statements are about homosexual men. The term 'homosexuals' will by most individuals be interpreted as referring to gay males and not to females (Haddock et al. 1993), so the items will predominantly measure attitudes toward gay men. As previously mentioned, heterosexuals tend to have quite different attitudes toward the two, with lesbians generally being viewed less negatively (e.g. Herek 2002; Kite and Whitley 1996). Hence, to better understand individual differences in attitudes toward homosexuality, researchers should distinguish between male and female homosexuals in their questions (Herek and Capitanio 1999; LaMar and Kite 1998; Kite and Whitley 1996).

A further consideration is whether participation biases influenced the results of the present study, especially as this survey queried participants about very personal information. Dunne et al. (1997) have examined this question for the survey used in the current study by comparing the social, psychological and behavioural features of the twins who explicitly consented to join the present study (52\%) with those who either explicitly refused $(27 \%)$ or initially agreed, but subsequently did not return the consent forms (19\%). Results indicate that those individuals who explicitly consented had less conservative sexual attitudes and were more likely to agree with gay rights. However, the effect sizes of these findings were small, indicating the participation bias probably did not influence the results to a great extent.

Another limitation to consider is the possibility of socially desirable responding. Although it is not possible to exclude social desirability effects, twins were encouraged to be honest by guaranteeing anonymity and by asking them to fill out the questionnaire while alone with sufficient privacy.

In summary, this study concerning the aetiology of homophobic attitudes revealed that familial aggregation in attitudes toward homosexuality is accounted for by genes as well as by shared environmental factors. However, when the plausible effect of assortative mating on our estimates is taken into account, familial aggregation for homophobia scores might be almost totally accounted for by genetic effects. More research is necessary to further unravel the sources of variance in homophobia and to determine whether these differ between sexes. This future research will need greater sample sizes-preferably including spouses - and should analyse attitudes toward male and female homosexuals separately. It will also be of interest to compare prejudice toward homosexuals with prejudice toward other targets (like racism and sexism), to see to what extent similar results will be obtained and whether the same genetic and environmental sources explain individual differences in prejudice toward different out-groups.

Acknowledgements This research was funded by a small grant (R03) to J.M.B. from the U.S. Institute of Mental Health (USA) and a small Commonwealth AIDS Research Grant to N.G.M. Twins participating in this study were drawn from the Australian NHMRC Twin Registry. K.J.H.V. was supported by an Honours Exchange Master of Neurosciences stipendiat of the CNCR (Amsterdam) and Erasmus Medical Centre (Rotterdam) and a fund from the Bekker-La BastideFonds (Rotterdam).

Open Access This article is distributed under the terms of the Creative Commons Attribution Noncommercial License which permits any noncommercial use, distribution, and reproduction in any medium, provided the original author(s) and source are credited.

\section{Appendix A. Attitudes to Homosexuality Questionnaire: Section C. Part 2 of 'Your Present Personality'}

In this part, answer YES if you agree with the statement, but answer NO if you disagree. Again, there are no right or wrong answers, and no trick questions. Work quickly and do not think too long about the exact meaning of questions.

Yes No

1. Homosexuality is merely a different kind of sexuality, and is not immoral.

2. Homosexual men should be allowed to work in the following professions:
a. Schoolteachers
b. Court judges
c. Ministers
d. Medical doctors
e. Government officials.

3. Homosexuals are dangerous as teachers or youth leaders, because they try to get sexually involved with children.

4. Homosexuality is obscene and vulgar.

5. Homosexuality is social corruption that can cause the downfall of civilization.

6. Homosexuals should be allowed to dance with each other in public areas.

\section{References}

Bierly MM (1985) Prejudice toward contemporary outgroups as a generalized attitude. J Appl Soc Psychol 15:189-199

Davies M (2004) Correlates of negative attitudes toward gay men: sexism, male role norms, and male sexuality. J Sex Res 41(3):259-266 
Dunne MP, Martin NG, Bailey JM, Heath AC, Bucholz KK, Madden PAF, Statham DJ (1997) Participation bias in a sexuality survey: psychological and behavioural characteristics of responders and non-responders. Int J Epidemiol 26(4):844-854

Eaves L, Heath A, Martin N, Maes H, Neale M, Kendler K, Kirk K, Corey L (1999) Comparing the biological and cultural inheritance of personality and social attitudes in the Virginia 30,000 study of twins and their relatives. Twin Res 2(2):62-80

Ekehammar B, Akrami N (2003) The relation between personality and prejudice: a variable- and a person-centred approach. Eur $\mathbf{J}$ Pers 17:449-464

Ekehammar B, Akrami N, Gylje M, Zakrisson I (2004) What matters most to prejudice: big five personality, social dominance orientation, or right-wing authoritarianism? Eur J Pers 18: $463-482$

Eysenck HJ (1976) Sex and personality. University of Texas Press, Austin

Falconer DS (1989) Introduction to quantitative genetics. Longman Scientific and Technical, Essex

Guimond S (2000) Group socialization and prejudice: the social transmission of intergroup attitudes and beliefs. Eur J Soc Psychol 30:335-354

Guimond S, Dambrun M, Michinov N, Duarte S (2003) Does social dominance generate prejudice? Integrating individual and contextual determinants of intergroup cognitions. J Pers Soc Psychol 84(4):697-721

Haddock G, Zanna MP, Esses VM (1993) Assessing the structure of prejudicial attitudes: the case of attitudes toward homosexuals. J Pers Soc Psychol 65(6):1105-1118

Hatemi PK, Alford JR, Hibbing JR, Martin NG, Eaves LJ (2007) Genetics and politics. Paper presented at the annual meeting of the midwest political science association. Chicago, March 2007

Heaven PCL, St. Quintin D (2003) Personality factors predict racial prejudice. Pers Individ Dif 34:625-634

Herek GM (1988) Heterosexuals' attitudes toward lesbians and gay men: correlates and gender differences. J Sex Res 25(4):451-477

Herek GM (2002) Heterosexuals' attitudes toward bisexual men and women in the United States. J Sex Res 39(4):264-274

Herek GM, Capitanio JP (1999) Sex differences in how heterosexuals think about lesbians and gay men: evidence from survey context effects. J Sex Res 36(4):348-360

Herek GM, Gonzalez-Rivera M (2006) Attitudes toward homosexuality among US residents of Mexican descent. J Sex Res 43(2):122-135

Jang KL, Livesley WJ, Vernon PA (1996) Heritability of the big five personality dimensions and their facets: a twin study. J Pers 64:577-591

Jellison WA, McConnell AR, Gabriel S (2004) Implicit and explicit measures of sexual orientation attitudes: ingroup preferences and related behaviors and beliefs among gay and straight men. Pers Social Psychol Bull 30(5):629-642

Jöreskog KG, Sörbom D (1999) LISREL 8.30 and PRELIS 2.30 for windows. Scientific Software, Chicago
Kendler KS, Thornton LM, Gilman SE, Kessler RC (2000) Sexual orientation in a US national sample of twin and nontwin sibling pairs. Am J Psychiat 157:1843-1846

Kirk KM, Bailey JM, Dunne MP, Martin NG (2000) Measurement models for sexual orientation in a community twin sample. Behav Genet 30(4):345-356

Kite ME, Whitley BE (1996) Sex differences in attitudes toward homosexual persons, behaviors, and civil rights: a meta analysis. Pers Soc Psychol Bull 22(4):336-353

Klassen AD, Williams CJ, Levitt EE (1989) Sex and morality in the US: an empirical enquiry under the auspices of the Kinsey Institute. Wesleyan University Press, Connecticut

LaMar L, Kite M (1998) Sex differences in attitudes toward gay men and lesbians: a multidimensional perspective. J Sex Res 35(2):189-196

Lingiardi V, Falanga S, D'Augelli AR (2005) The evaluation of homophobia in an Italian sample. Arch Sex Behav 34(1):81-93

Loehlin JC, McCrae RR, Costa PT Jr, John OP (1998) Heritabilities of common and measure-specific components of the big five personality factors. J Res Pers 32:431-453

Martin NG (1978) Genetics of social and sexual attitudes. In: Nance WE (ed) Twin research: psychology and methodology. Alan R. Liss Inc., New York, pp 13-23

Martin NG, Martin PG (1975) The inheritance of scholastic abilities in a sample of twins: I Ascertainment of the sample and diagnosis of zygosity. Ann Hum Genet 39:213-218

Martin NG, Eaves LJ, Kearsey MJ, Davies P (1978) The power of the classical twin study. Heredity 40:97-116

Martin NG, Eaves LJ, Heath AC, Jardine R, Feingold LM, Eysenck HJ (1986) Transmission of social attitudes. Proc Natl Acad Sci U S A 83(12):4364-4368

Merriam-Webster's Medical Dictionary (2007) Definition Homophobia. Retrieved 16 May 2007, from Dictionary.com website: http://dictionary.reference.com/browse/homophobia

Neale MC, Cardon LR (1992) Methodology for genetic studies of twins and families. NATO ASI series: behavioral and social sciences. Kluwer, Dordrecht

Neale MC, Eaves LJ, Kendler KS (1994) The power of the classical twin study to resolve variation in threshold traits. Behav Genet 24(3):239-258

Neale MC, Boker SM, Xie G, Maes HH (2003) Mx: statistical modelling, 6th edn. Department of Psychiatry, Medical College of Virginia, Richmond

Ooki S, Yamada K, Asaka A, Hayakawa K (1990) Zygosity diagnosis of twins by questionnaire. Acta Genet Med Gemellol (Roma) 39(1):109-115

Reynolds KJ, Turner JC, Haslam SA, Ryan MK (2001) The role of personality and group factors in explaining prejudice. J Exp Soc Psychol 37:427-434

Steffens MC, Wagner C (2004) Attitudes toward lesbians, gay men, bisexual women, and bisexual men in Germany. J Sex Res 41(2):137-149 